\title{
Quality Assurance in Our Health Care System
}

\author{
Avedis Donabedian, ${ }^{*}$ M.D., M.P.H. \\ School of Public Health, Department of Medical Care Organizaton, The University of Michigan, Ann Arbor, Michigan
}

Quality assurance is not a luxury that we may or may not choose to acquire. It is a necessity that embodies our commitment and obligations as a society, in general, and as health care professionals, in particular. It is important, therefore, to understand what quality assurance entails, to examine how we have performed in its pursuit, and what more may need to be done to realize it in larger measure. This paper is meant to offer a modest contribution to selfexamination and reform.

\section{DEFINING QUALITY}

I shall consider the quality of care to be proportional to its ability to achieve desired improvements in health and well-being under circumstances that are pleasing to its recipients as well as socially approved. Quality can be seen, therefore, to comprise at least four components: 1) the technical management of health and illness, 2) the management of the interpersonal relationship between the providers of care and their clients, 3) the amenities of care, and 4) the ethical principles that govern the conduct of affairs in general and the health care enterprise in particular.

All of these aspects of care, as well as the consequences to which they contribute, are subject to assessment not only by health care practitioners, but also by clients and by representatives (more or less convincingly legitimate) of the public interest. The estimate of quality can vary, therefore, depending on who makes the assessment. Health care professionals are more alert to the technical components of the process of care. Clients are more impressed by the outcomes of care, by the niceties of the interpersonal process, and by the amenities of care (1). Client sat-

\footnotetext{
* Nathan Sinai Distinguished Professor of Public Health.
}

isfaction remains, nevertheless, an important outcome of care, as well as a judgment of its quality.

The judgment of quality varies also according to the level of analysis. Health care practitioners are concerned with the welfare of their patients, and patients are concerned with their own health and well-being. But at the social level of analysis, citizens, in general, and representatives of the public interest, in particular, should be concerned also with the social distribution of access to care, of the quality of care, and of the improvements in health that hinge on access and quality. A similar distinction characterizes the concern for monetary cost, patients being concerned with what they themselves pay, whereas society, and the agencies that represent it, must consider the magnitude and social distribution of the costs that everyone must shoulder.

\section{QUALITY AND COST}

Perhaps the most important thing to remember about the relation between cost and quality is that quality costs money. It is also true, however, that care is often provided wastefully, and that some of it can be actually harmful. By reducing the occurrence of wasteful and harmful care we could reduce cost without injury to quality. But, after wasteful and harmful care are eliminated, any further improvements in quality would require additional expenditures. The added improvements in quality that would follow would not always be commensurate with the added cost. There comes a time when large increments of cost result in rather small improvements in health. So, when does one stop in this progression of added costs with diminishing returns? The answer varies.

An individual patient who pays all the cost and garners all the benefit of care may decide to stop at a point short of the full benefit that science can bestow, 
doing so because the cost may have become prohibitive. While this is perfectly reasonable behavior, it could be socially unacceptable, since it means that there is one specification of quality for the poor and another, at a higher level of benefit, for the rich. But if, in response to this unacceptable distinction, society agrees to shoulder, as it has, more of the cost of care for everyone, individuals will demand more care, while society, which is burdened by the cost, wishes to provide less. This conflict between the short run interests of individuals and the public good is, ultimately, the fundamental dilemma facing cost containment (2).

\section{QUALITY ASSURANCE}

There are two ways of defining "quality assurance," one very broad and another more narrow, although still rich in content.

\section{An Inclusive Definition}

More broadly defined, quality assurance includes all the arrangements and activities that are meant to safeguard, maintain, and promote the quality care. If so, there is almost nothing in a health care system that is not, in one way or another, pertinent. Here are some examples.

Included under a broad definition of quality assurance are almost all characteristics of health care personnel: recruitment, education, postgraduate training, specialization, licensure and relicensure, certification and recertification, continuing education, intrainstitutional organization (including scope of legitimate activities permitted), and also numbers and geographic location. There is a list of analogous attributes pertinent to the facilities needed for health care personnel to work in. The drugs, biologicals, instruments, and equipment used in diagnostic and therapeutic management are themselves subject to social control with a view to assuring both efficacy and safety.

Also included under a broad definition of quality assurance are the arrangements under which clients obtain access to care and health care personnel are remunerated. This includes the scope of benefits under health insurance plans and government programs, the eligibility of clients for such benefits, the degree to which clients have to pay deductibles or make copayments, the conditions under which practitioners and institutions may participate as providers, and the manner in which the providers are organized and paid.

Then there are the activities directed at educating consumers to select their sources of care more wisely, to demand care more appropriately, and to participate more effectively in their own care. One might also add certain legal safeguards, such as liability and malpractice laws, as playing a role in quality assurance, although the fear of malpractice suits is also mentioned as one reason for wasteful care (3).

Many other items could be added to the foregoing list, but enough has been said to demonstrate how allembracing quality assurance can be when viewed in this inclusive way. It is perhaps more reasonable to adopt a narrower definition.

\section{A Narrower Definition}

A more modest definition of quality assurance includes only those activities that periodically or continuously review the conditions under which care is provided, the care itself is monitored, and the outcomes of care are tracked, so that deficiencies may be noted, the reasons for these deficiencies discovered, and the necessary corrections made, resulting in improvements in health and well-being. Quality assurance, in this sense, is a cyclical process. It begins with information about the system of health care and its performance, leads to changes in the system, then to further review of performance, and so on, without end; eternal vigilance being the condition for quality as for so many of the other things we value.

Most systems of quality assurance are meant to assess what happens after people become patients. They generally collect two kinds of information. The first is information about whether or not health care practitioners and facilities meet certain standards of qualifications, staffing, equipment, space, safety, record keeping, organization, and so on. The activities of the Joint Commission on Accreditation of Hospitals are a good example.

The second type of information for quality monitoring concerns what is actually done for patients and what the consequences are. There are, obviously, many ways in which this information can be obtained, assembled, presented, analyzed, and interpreted. The activity can be performed under many auspices. It can be undertaken (indeed, should be undertaken) as an "internal" activity by the organized providers themselves, the most important of these being hospitals and Health Maintenance Organizations. The monitoring of activities can also be "external," being conducted by such organizations as insurance agencies, government bureaus, or governmentally mandated, quasi-public bodies such as the now defunct Professional Standards Review Organizations or the Peer Review Organizations that have replaced them. 


\section{THE RECORD OF SYSTEM PERFORMANCE}

Using the preceding, perhaps too familiar, account as a backdrop, I would like, next, to offer some personal impressions of how our system has performed insofar as some aspects of quality are concerned.

\section{Consumer Satisfaction}

Studies of consumer opinion regularly reveal very high levels of satisfaction with health care in general, as with many of its specific aspects, including its quality. Consumers are also seemingly loyal to their own physicians, reporting greater satisfaction with them than with physicians in general.

There are, of course, some things that consumers desire, but do not always get: easier access, less waiting, more time with the physician, more explanations by the physician, seeing the same physician each time they visit, and so on. But the general picture is one of approval. There is no evidence of the widespread discontent that the pronouncements of professional reformers might lead one to expect (see Refs. 4-10).

There are developments, nevertheless, that could trouble this almost idyllic picture. The patient-practitioner bond appears as somewhat weakened in for: mal organizations such as prepaid group practices; and the relation is likely to be further jeopardized if patients perceive that practitioners : are withholding care in obedience to organizational or societal economies that are contrary to the immediate self-interest of patients (11-13).

Other efforts at cost containment are also likely to alter the picture. Of all the attributes of care, the least satisfaction is associated with cost. People, in fact, feel that insurance coverage is inadequate, they want more protection, and mostly do not care whether that protection is offered by governmental programs :or private enterprise (6). At the same time, people generally support many recent cost containment activities as well (10). I believe this is because people see these activities as only cutting waste and affecting mainly the revenue of hospitals and the income of physicians. People have not understood that cost containment may mean that they, themselves, may: be denied certain kinds of care that they feel they need and deserve. When they do understand, their anger could be hard to contain.

\section{Social Distribution of Access and Quality}

Viewed from a societal perspective, there has been a remarkable improvement in the social distribution of access to care. Now, by and large, the poor receive more services than the well-to-do, with the notable exception of dental care. It is believed, however, that even now, when compared to their health status or perceived need for care, the poor receive less service than they should. There may also be a group of people, precariously situated between poverty and sufficiency, who are hardest hit (8).

As to the quality of care received subsequent to access having been gained, the evidence is fragmentary and totally inconclusive. It is likely that the poor and underprivileged receive care in rather less pleasant circumstances. As to technical services, the mix of the sources of care is somewhat different, being weighted toward generalists, hospital clinics, and a hospital's resident staff. The consequences of these biases, although perhaps sometimes adverse, need not be so in all cases. But it may be that we know so little about this subject because we have not dared to look. It is time to lift the veil $(14,15)$.

If there are deficiencies in access or of quality after access has been accomplished, the consequences should show in indicators of health. But, because health status is influenced by many factors other than health care, it is difficult to make judgments concerning quality and access by measuring the health of a population. We also need to remember that while poverty causes ill health, ill health can also cause poverty; or it may be that both poverty and ill health are the effects of yet another factor, such as old age, which is associated with both.

Whatever the causes might be, we still observe considerable differentials in mortality and disability among people in different socioeconomic categories $(16,17)$. For example, the disparity in infant mortality between blacks and whites has progressively narrowed in absolute terms, but in relative terms the gap has not narrowed, and may even have widened $(18,19)$.

\section{Public Policy on Quality and Cost}

The rhetoric of public discourse, and the policy that both generates that discourse and stems from it, have emphasized the wastefulness of health care-a wastefulness that is seen to result from the availability of health insurance, on the one hand, and in retrospect, service-related methods of reimbursement, on the other. We have lost sight of the many additions to care that need to be made. We have a great deal of evidence that there are such deficiencies. By contrast, our information about the prevalence of wasteful practice tends to be sparse, anecdotal, and indirect. We know, for example, that prepaid group practices reduce certain types of surgery and other hospital use (20). 
We expect second surgical opinion programs to reduce the costs attendant on elective surgery by about $5 \%$ (extrapolated based on McCarthy et al. (21)). But we do not know, for certain, what the impact of a fully successful quality assurance program would be on the cost of a representative sample of hospital admissions-what would be saved by cutting out wasteful care, and what would need to be added to rectify insufficient care. It is time to find out.

We have not even begun to face up to the grim prospect of the problems that stem from denying care from which patients would benefit because we cannot afford it.

\section{Quality Assurance through System Design}

There is an almost endless list of issues to be discussed if one wishes to assess how successful we have been in assuring quality through system design. Only a few of these can be mentioned in this brief assessment.

Health Practitioners. When one considers the contribution of health practitioners, the most important issue is perhaps that of their appropriate education and training. There is, however, something else that comes first. The science of clinical practice which future practitioners are to learn, through precept and example, must itself be reformed through a respecification of the objectives of health care and of the means of attaining the objectives.

As to the objectives, we require a more inclusive definition of health, and an orientation to managing health rather than to dealing only with illness. As to the means, a massive enterpise is needed to discover, specify, and teach strategies of care that are efficient as well as effective. We cannot afford to go on defining quality independently of monetary cost. We already have demonstrations that we can achieve equal or superior health care results at lower cost, sometimes by rather simple reformulation of the strategies of care (see for example, Brand (22) and Doubilet and Abrams (23)). In my opinion, this is the highest priority in clinical research today. To the extent that we succeed in finding more efficient strategies of care, we. will at least postpone the necessity of withholding useful care from some because we cannot afford it.

Facilities. Under the heading of facilities, I believe the major problem has been our inability to create a differentiated, yet balanced and coordinated, system so that patients can be placed in the least costly but effective site of care, with assurance that as the patient's needs change, there will be easy transfer from site to site without loss of coherence or sacrifice to quality.
One of the paradoxes of quality monitoring is that we have concentrated it on, and in, the hospitals, the institutions which, in some ways, need it the least. The reasons for this are obvious and legitimate. But at the same time, nursing homes, where the monitoring of process and outcome is most needed, have gone virtually without. This is a deficiency that requires even more urgent attention today when, under prospective reimbursement, sicker patients will be sent to even more ill-prepared nursing homes more often. But, closer monitoring will not, by itself, be the answer. What may be needed is a major structural change, a change sometimes called "vertical integration." Whether that occurs under private, quasi-public, or public auspices is something to debate. My tendency would be to encourage all forms, and to judge by the results, rather than by obedience to ideological prejudice.

Organization of Financing. When we consider the organization of financing we encounter a widespread belief that health insurance is to blame for the escalation of prices, accompanied by considerable increase in "unnecessary" care. There are, therefore, many proposed reforms the purpose of which is to influence people to buy less complete coverage, and to shoulder more of the burden of cost through out-of-pocket payments. These measures are supposed to make people more prudent purchasers, reducing cost without injuring quality.

In my opinion such an expectation is based on largely unwarranted assumptions: $(a)$ that people know how to buy the right amount of insurance coverage; (b) that they will shop for a source of care each time a major illness strikes, based on a knowledge of prices, services to be rendered in the future, and quality; and (c) that once the source of care has been selected, the client can successfully, second-guess the physician, accepting or rejecting the recommendations of the physician on the grounds of a personal costbenefit analysis.

These and some other components of the competitive model are, in my opinion, only a beautiful, seductive myth. Besides, as we saw earlier, they do not correspond to what most people say they wish to have. The proposals to modify health insurance in the.ways I described are more likely, I believe, to reduce access to care, to do so particularly for the middle class, and to injure quality (24).

Prospective Reimbursement. This is a measure that; no doubt, will rectify the many abuses of the system of reimbursement that it replaces. But, while it deals with old abuses, it introduces the threat of new ones. If previously we had overservicing and an escalation in cost, we now face the danger of underservicing, underequipment, undermaintenance of resources, and 
a deterioration in the amenities. Besides, the hospitals may be as preoccupied with devising means to outwit the system as with improving efficiency.

After a brief honeymoon during which prospective payment was seen as the self-regulating mechanism that would eliminate the need for external regulation, we began to realize that we were going to need more monitoring and regulation if cost was to be reduced without damage to quality. That is why after killing off the Professional Standards Review Organizations we had to call them back to life again in the form of the Peer Review Organization-an organization with an even sterner purpose, and one more likely to be separate from, and hostile to physicians and hospitals.

If I were to be concerned only about quality, without regard to cost, I would probably prefer retrospective reimbursement, accompanied by strict monitoring, to prospective reimbursement accompanied by equally strict monitoring. Prospective reimbursement would be preferred only if one had a deep faith in the probity and integrity of health are practitioners. We would have to believe that while health care practitioners might allow themselves to be wasteful, they would simply not permit a reduction in the quality of care; every other form of cost cutting would be practiced rather than allow quality to be compromised. Stated as a near paradox, we would not trust physicians and administrators with money, but we would trust them with quality, at least up to a point. It is this thin end of the wedge of doubt that accounts for the reincarnated advent of the Peer Review Organizations!

\section{Quality Assurance through Monitoring}

It is clear from the immediately preceding analysis that the monitoring of quality plays a key role in any assessment of our future prospects. In other words, much depends on "quality assurance" as more narrowly defined.

In this respect, the first observation to be made is that our system of quality monitoring has largely centered on patient care and, as was pointed out earlier, on a limited part of patient care at that: namely, the hospital inpatient segment. It is possible, however, to widen the scope of concern so it includes the community as a whole, by collecting and analyzing data on access to care; subsequent utilization; the occurrence of preventable morbidity, disability, and mortality; the preventable progression of disease; and so on. We have the knowledge and the methods. What we need is to identify a clear locus of responsibility and to assure the corresponding authority and resources.

When we assess the monitoring of patient care we find, once again, that we have a large arsenal of methods (15). What seems to be lacking is the capacity to make them work. The record of the Professional Standards Review Organizations is an excellent example. After nearly 10 years, there was still no conclusive evidence that, taken as a whole, they had accomplished anything but spend a great deal of money (25). Perhaps this was because the Professional Standards Review Organizations were controlled by physicians, and many activities of Professional Standards Review Organizations were delegated to the hospitals themselves. The Professional Standards Review Organizations were, largely, an exercise in self-regulation that for lack of skill, or a wavering of will, or for other reasons, seems to have failed. And yet, there were many individual Professional Standards Review Organizations that succeeded notably in reducing unnecessary utilization, returning a large dividend for each dollar spent on monitoring (see for example, Ref. 26). Unfortunately, we cannot be anywhere as sure about their accomplishments in improving quality.

Based on the record of performance of at least some components of this nationwide enterprise, and on the results of many, much smaller, local experiences, I would conclude that although many improvements can still be made, we now have potentially effective methods for monitoring quality and utilization. Perhaps what we need to make these methods work is a system of monitoring that forms part of more fundamental reform in the structure of the health care system itself.

\section{SOME PROPOSALS FOR SYSTEM REFORM}

In contemplating a more fundamental reforming of the system what we seek is some way to coordinate at least three major functions: 1 ) the production and delivery of care, 2) the financing of care, including the methods of reimbursement, and 3) the monitoring and adjustment of performance. As a means of achieving this objective we could, of course, adopt a rather radical posture by proposing a national health service. We could, then, have both the opportunity and the means to design what some would call a "rational" system. But, on the whole, we are wary of such revolutionary change.

In a search for something more modest, I and many others are attracted to the notion of organizing the system around Health Maintenance Organizations of the group practice model integrated with hospitals, nursing homes, home care services, and other supportive activities. Complexes of this kind are to be prepaid on a per capita basis, and expected to accept total responsibility for the health care of their enrollees. These complexes can effectively monitor the cost and 
the quality of the care they provide. But there should also be an external monitoring of performance under public auspices, employing data on cost, on use of services, and on health status.

In such schemes, consumers' interests would be represented in two ways: first, by formal participation of consumers in policy formulation and planning, and secondly, through competitive free choice. But for free choice to succeed in regulating the system, it is important for consumers to have impartial and accurate information about the performance of the available providers. This means that the results of external monitoring will not merely be made available, but actually publicized.

Under these circumstances, assuming they could be realized, we would expect competition to be effective. Prepaid group practices are more manageable objects of free choice, assuming there are enough of them to allow a choice. This is because they can be more easily identified and described; because the services they provide and the cost of these services are more precisely determinable in advance; and because the performance of the organization can be more readily assessed and publicized, both as to the process of care and its impact on health.

There is reason to believe that market forces are, of their own accord, moving us in the direction I have described. We should remember, however, that the profit motive does not, in and of itself, assure the attainment of broader social objectives. Indeed, evidence for the good things we believe Health Maintenance Organizations can accomplish comes almost entirely from the experience of prepaid group practices motivated not by the pursuit of profit but by the spirit of service. We will need, therefore, a judicious mix of private enterprise (profit-oriented or service-oriented) and of public guidance and supervision. Whether we shall succeed in finding this felicitous middle course, and whether, it will take us where we wish to go, remains to be seen.

In the last analysis, it is individuals that make any . system succeed or fail. No system design, however judicious or elegant, can make up for a failure in honesty, dedication, and goodwill in those who have to make it work.

Am I saying, when all is said and done, we must, ultimately, fall back on the fundamental moral resources of each individual? That we need, so to speak, to be "born again"? My answer, quite simply, is "Yes."

\section{ACKNOWLEDGMENTS}

This paper is based on a presentation made at the First Annual Follow-up Meeting, Kellogg Pharmaceu- tical Scientist Program, University of Georgia Center for Continuing Education, Athens, Georgia, April 25, 1985. The work on which the paper is based has been supported at various times by the National Center for Health Services Research, the Commonwealth Fund, and the W. K. Kellogg Foundation.

\section{References}

1. Donabedian A. Explorations in Quality Assessment and Monitoring. Ann Arbor, MI, Health Administration Press, 1980, Vol. I, pp 35-74.

2. Donabedian A, Wheeler JRC, Wyszewianski L. Quality, cost, and health: an integrative model. Med Care 1982;20:975-992.

3. Brook RH, Brutoco RL, Williams KN. The Relationship Between Medical Malpractice and Quality of Care. Santa Monica, CA, The Rand Corporation, 1975.

4. Ware JE, Snyder MK. Dimensions of patient attitudes regarding doctors and medical care services. Med Care 1975;13:669682.

5. Robert Wood Johnson Foundation. America's Health Care System: A Comprehensive Portrait. Princteon, NJ, Robert Wood Johnson Foundation, 1978, Special Report No. 1.

6. Health Insurance Institute. Health and Health Insurance: The Public's View. Washington, DC, Health Insurance Institute, December 1980.

7. Aday LA, Andersen R, Fleming GV. Health Care in the U.S.: Equitable for Whom? Beverly Hills, CA, Sage Publications, 1980.

8. Aday LA, Andersen RM. Equity of access to medical care: a conceptual and empirical overview. Med Care 1981;19:4-27 (suppl).

9. Andersen RM, Fleming GV, Champney TF. Exploring a paradox: belief in a crisis and general satisfaction with medical care. Milbank Mem Fund Q Health Soc 1982;60:329-354.

10. Health Insurance Association of America. Health and Health Insurance: The Public's View. Washington, DC, Health Insurance Association of America, 1984.

11. Freidson E. Patients' Views of Medical Practice. New York, Russell-Sage Foundation, 1961, Chaps. 9 and 10.

12. Freidson E. Prepaid group practice and the new 'demanding patient'. Milbank Mem Fund Q Health Soc 1973;51:473-448.

13. Mechanic D. The Grouth of Bureaucratic Medicine. New York, John Wiley and Sons, 1976, Chap. 3.

14. Wyszewianski L, Donabedian A. Equity in the distribution of quality of care. Med Care 1981;19:28-56 (suppl).

15. Donabedian A. Explorations in Quality Assessment and Monitoring. Ann Arbor, MI, Health Administration Press, 1985, Vol. III, pp 463-471.

16. Lerner $M$, Stutz RN. Have we narrowed the gaps between the poor and the non poor? Part II. Narrowing the gaps, 1959-1961 to 1969-1971: mortality. Med Care 1977;15:620-635.

17. Newacheck PW, Butler LH, Harper AK, Piontkowski DL, Franks PE. Income and illness. Med Care 1980;18:1163-1176.

18. Wegman ME. Annual summary of vital statistics -1979 : with some 1930 comparisons. Pediatrics 1980;66:823-833.

19. Wegman ME, Annual summary of vital statistics-1983. Pediatrics 1984;74:981-990.

20. Luft HS. Assessing the evidence on HMO performance. Milbank Mem Fund Q Health Soc 1980;58:501-536.

21. McCarthy EG, Finkel ML, Ruchlin HS. Second Opinion Elective Surgery. Boston, Auburn House Publishing, 1981, pp 113-152.

22. Brand DA. An X-ray Screening Protocol for Extremity Injuries. Rockville, MD, National Center for Health Services Research, Research Report Series, DHHS Publication No. (PHS) 843347 , Septemer 1984.

23. Doubilet $\mathrm{P}$, Abrams HL. The cost of underutilization: percuta- 
neous transluminal angioplasty for peripheral vascular disease. N Engl J Med 1984;310:95-102.

24. Wyszewianski L, Wheeler JRC, Donabedian A. Market-oriented cost-containment strategies and quality of care. Milbank Mem Fund Q Health Soc 1982;60:518-550.

25. Lohr KN, Brook RH. Quality Assurance in Medicine: Experience in the Public Sector. Santa Monica, CA, The Rand Corporation, 1984.

26. Health Care Financing Administration, Office of Policy, Planning and Research. Professional Standards Review Organizations, 1978 Program Evaluation. Washington, DC, U.S. Government Printing Office, January 1979, pp 177-181. 